\title{
The Influence of Electrospinning Parameters and Drug Loading on Polyhydroxyalkanoate (PHA) Nanofibers for Drug Delivery
}

\author{
Yan-Fen Lee ${ }^{1}$, Nanthini Sridewi ${ }^{2}$, Surash Ramanathan ${ }^{3}$ and Kumar Sudesh ${ }^{1, *}$ \\ ${ }^{1}$ Ecobiomaterial Research Laboratory, School of Biological Sciences, Universiti Sains Malaysia, Minden \\ 11800 Penang, Malaysia \\ ${ }^{2}$ Department of Maritime Science and Technology, Faculty of Defence Science and Technology, National \\ Defense University of Malaysia, Sungai Besi Camp, 57000 Kuala Lumpur, Malaysia
}

${ }^{3}$ Centre for Drug Research, Universiti Sains Malaysia, 11800 Minden Penang, Malaysia

\begin{abstract}
The impact of polymer concentration and drug loading on nanofiber morphology and diameter were investigated during electrospinning of polyhydroxyalkanoate nanofibrous films. Low molecular weight poly(3hydroxybutyrate-co-4-hydroxybutyrate) $[\mathrm{P}(3 \mathrm{HB}-\mathrm{co}-95 \mathrm{~mol} \% 4 \mathrm{HB})]$ required a 5 -fold higher solution concentration than high molecular weight poly(3-hydroxybutyrate) $[\mathrm{P}(3 \mathrm{HB})]$ to produce bead-free nanofibers. Loading the films with paclitaxel increased the initial polymer solution viscosity allowing larger diameter nanofibers to form. Furthermore, paclitaxel added at $1 \%(\mathrm{w} / \mathrm{w})$ into $8 \%(\mathrm{w} / \mathrm{v}) \mathrm{P}(3 \mathrm{HB}-\mathrm{co}-95 \mathrm{~mol} \% 4 \mathrm{HB})$ solution eliminated the formation of beads seen in solutions without the drug, at the same initial polymer solution concentration. In preliminary drug release studies, nanofiber mats consisting of large-diameter nanofibers with high drug loading released paclitaxel at a faster rate due to larger pore sizes. This was a consequence of the random packing of larger diameter nanofibers. However, the release pattern of nanofibers with low drug loading was much more consistent and controlled. Lastly, we have shown the potential applications of $\mathrm{P}(3 \mathrm{HB}-\mathrm{co}-4 \mathrm{HB})$ drug loaded nanofibers in the development of biocompatible drug eluting stents by directly coating a metal stent with a homogeneous layer of electrospun polymer.
\end{abstract}

Keywords: polyhydroxyalkanoate, electrospinning, nanofibers, drug loading, biocompatibility.

\section{INTRODUCTION}

Biomimetic nanofibrous scaffolds have gained in popularity for use in many biomedical applications owing to their structural and mechanical properties that mimic the extracellular matrix of biological systems [1]. To date, many techniques have been reported for the fabrication of nanofibrous scaffolds including electrospinning, self-assembly and phase separation [2]. Among these techniques, electrospinning is a relatively simple and robust production method. Electrospinning has become a widely used and relied-upon method because it allows the production of different alignment scaffolds of ultra-fine fibers, ranging from nano- to microscale in diameter, from a wide range of natural and synthetic polymers. This in turn has encouraged the use of various biodegradable and/or biocompatible polymer materials as fiber matrices for use in drug delivery, wound healing, tissue engineering, biosensors and many other applications [2-6].

Many polymers such as polylactic acid (PLA), polyethylene glycol (PEO), polyurethane, polyethyleneco-vinyl acetate (PVA) and cellulose acetate have been electrospun to form fibers for drug delivery [5]. In the

*Address correspondence to this author at the Ecobiomaterial Research Laboratory, School of Biological Sciences, Universiti Sains Malaysia, Minden 11800 Penang, Malaysia; Tel: +604 6534367; E-mail: ksudesh@usm.my present work, polyhydroxyalkanoates (PHAs) were electrospun to create fibrous films. PHAs are a class of biodegradable polyesters synthesized by microorganisms under unfavorable growth conditions. They have been widely evaluated as biomaterials, in part due to their advantageous bio-mechanical characteristics and biocompatibility [7]. Microorganisms can polymerize about 150 different monomers into PHAs, thus offering a wide selection of mechanical and biochemical properties for various applications $[8,9]$. Poly(3-hydroxybutyrate) $[\mathrm{P}(3 \mathrm{HB})]$ is the most common PHA that has been studied both intensively and extensively. However, its stiff characteristic has been a limiting factor for use in some applications. Hence, the copolymerization of one or more monomers in PHA could offer better characteristics, as PHA copolymers are known to be less crystalline and more elastic. Several PHAs have been evaluated as biomaterials in the areas of wound management, tissue engineering, drug delivery, cardiovascular remediation (artery augmentation, pericardial patches, cardiovascular stents and atrial septal defect repair), nerve regeneration and orthopedic applications. Of these PHAs, poly(3-hydroxybutyrate-co-4-hydroxybutyrate) $[\mathrm{P}(3 \mathrm{HB}-\mathrm{co}-4 \mathrm{HB})]$ is often nominated as a good candidate for use in biomedical applications since it has excellent biocompatibility in the human body and is well tolerated in vivo [10-13]. The hydrolysis products of $\mathrm{P}(3 \mathrm{HB}-\mathrm{CO}-4 \mathrm{HB})$ are $3 \mathrm{HB}$ and $4 \mathrm{HB}$ monomers, which 
are natural metabolites that exist in the brain, lung, heart, liver, kidney and muscle [14] and could be removed as expired carbon dioxide from the human body via the tricarboxylic acid (TCA) cycle [15]. Thus, $\mathrm{P}(3 \mathrm{HB}-\mathrm{Co}-4 \mathrm{HB})$ was selected for the present study to investigate the potential for drug delivery using electrospun nanofibers.

A wide range of drugs can be incorporated directly into different sizes or types of fibers for site-specific drug delivery [16]. In our study, we targeted paclitaxel as the model for the drug effect on fiber morphology and drug release studies. Paclitaxel is a lipophilic/hydrophobic drug which has been approved by the Food and Drug Administration of the United States of America (FDA) for use as an anti-tumor agent for many cancers including ovarian, breast, and nonsmall cell lung cancer, head and neck cancer, leukemia and melanoma [17-21]. However, current formulations used to deliver paclitaxel in the human body may cause several side effects such as hypersensitivity reaction, nephrotoxicity, neurotoxicity and cardiotoxicity [22]. Our aim was therefore to develop PHA-based nanofibers for paclitaxel accommodation and delivery to serve as an alternative approach to overcome the abovementioned problems.

\section{MATERIALS AND METHODS}

\subsection{Materials}

Bacterial strain, Delftia acidovorans (JCM 10181) and $\mathrm{P}(3 \mathrm{HB})$ were kindly provided by Prof. $\mathrm{Y}$. Doi from RIKEN, Japan and members of the Ecobiomaterial Research Laboratory, respectively. Paclitaxel was purchased from Chemtron Biotechnology (Singapore). Glucose, magnesium sulphate $\left(\mathrm{MgSO}_{4} \cdot 7 \mathrm{H}_{2} \mathrm{O}\right)$ and $1,4-$ butanediol were used for biosynthesis of PHA. Chloroform $\left(\mathrm{CHCl}_{3}\right)$ (HPLC grade), methanol (HPLC grade), acetonitrile (HPLC grade) and dimethylformamide (DMF) (analytical grade) were purchased from Fisher Scientific (USA).

\subsection{Production of $\mathrm{P}(3 \mathrm{HB}-\mathrm{co}-95 \mathrm{~mol} \% \mathrm{4HB}) \mathrm{Via}$ Two-Stage Cultivation}

$\mathrm{P}(3 \mathrm{HB}-\mathrm{co}-95$ mol\% $4 \mathrm{HB})$ was biosynthesized according to the method reported by Lee et al. [23]. $D$. acidovorans was cultivated to produce $\mathrm{P}(3 \mathrm{HB}-\mathrm{co}-95$ mol\% $4 \mathrm{HB}$ ) by feeding the bacterium with 1,4butanediol as the sole carbon source to induce the accumulation of $\mathrm{P}(3 \mathrm{HB}-\mathrm{co}-95 \mathrm{~mol} \% 4 \mathrm{HB})$ via two-stage cultivation. In order to ensure that $\mathrm{P}(3 \mathrm{HB}-\mathrm{co}-95 \mathrm{~mol} \%$ $4 \mathrm{HB}$ ) was pure without any traces of bacterial residual matter, the extraction and purification were carried out according to the methods described by Siew et al. [12, 13]. The PHAs that were extracted using this method were shown to have good biocompatibility.

\subsection{Analytical Procedures}

PHA composition was analyzed according to the standard procedures [24]. Approximately $15-25 \mathrm{mg}$ of freeze-dried cells were suspended in a methanolysis solution containing $15 \%(\mathrm{v} / \mathrm{v})$ sulfuric acid and $85 \%$ $(\mathrm{v} / \mathrm{v})$ methanol and heated at $100{ }^{\circ} \mathrm{C}$ for $140 \mathrm{~min}$. The resulting hydroxyacyl methyl esters were analyzed via gas chromatography (GC). The weight average molecular weight $\left(M_{\mathrm{w}}\right)$, number average molecular weight $\left(M_{n}\right)$ and polydispersity index $\left(M_{w} / M_{n}\right)$ (PDI) of the PHAs were determined using Gel-Permeation Chromatography (Agilent 1200 GPC). The analysis utilized a refractive index detector, Shodex K-806 M and $\mathrm{K} 802$ columns at $40{ }^{\circ} \mathrm{C}$ at a flow rate of $0.8 \mathrm{~mL} / \mathrm{min}$ with $\mathrm{CHCl}_{3}$ (HPLC grade, filtered) as the eluent. The polymers were dissolved in HPLC grade $\mathrm{CHCl}_{3}$ to a concentration of $1.0 \mathrm{mg} / \mathrm{mL}$ and the solution was filtered prior to GPC analysis. Polystyrene standards with a low polydispersity were used to obtain a calibration curve.

\subsection{Fabrication of Electrospun PHA Fibrous Films}

Precursor PHA solutions were prepared at concentrations of $2 \%, 8 \%$ and $10 \%(\mathrm{w} / \mathrm{v})$ prior to electrospinning, according to formula (1): -

Polymer solution concentration $(\%)=$ [mass of polymer $(w) \div$ solvent volume $(v)] \times 100$

The studied PHAs were dissolved in a binary solvent system comprised of $\mathrm{CHCl}_{3}$ and DMF at a ratio of $4: 1$. Subsequently, $1 \mathrm{~mL}$ of precursor PHA solution was loaded into a $1 \mathrm{~mL}$ glass syringe and electrospun using an Esprayer ES-2000S (Fuence Ltd. Co). Different voltages ranging from $10-30 \mathrm{kV}$ were applied at a fixed flow rate of $40 \mu \mathrm{L} / \mathrm{min}$. The distance from the tip of the syringe to the metal collector was maintained at $20 \mathrm{~cm}$. Fibers were deposited and collected on a $2 \mathrm{~cm} \times 2 \mathrm{~cm}$ aluminium foil positioned on the metal collector at the end of the process.

\subsection{Loading of Paclitaxel into Electrospun $\mathrm{P}(3 \mathrm{HB}$ - co-95 mol\% 4HB) Fibrous Film}

$\mathrm{P}(3 \mathrm{HB}-\mathrm{co}-95 \mathrm{~mol} \% \mathrm{4HB})$ solutions at concentrations of $8 \%$ and $10 \%(\mathrm{w} / \mathrm{v})$ were prepared according to formula (1) above. The loading 
percentage of paclitaxel into $\mathrm{P}(3 \mathrm{HB}-\mathrm{co}-95 \mathrm{~mol} \% 4 \mathrm{HB})$ nanofibers was set to range from $1 \%$ to $5 \%$ according to the polymer mass. The polymer solutions containing paclitaxel were electrospun as described above. A voltage of $25 \mathrm{kV}$ was set to supply electrostatic force, at a fixed flow rate of $40 \mu \mathrm{L} / \mathrm{min}$. Fibers were collected on a $2 \mathrm{~cm} \times 2 \mathrm{~cm}$ aluminium foil placed on the metal collector. Next, the fibrous films were vacuumed for approximately $72 \mathrm{~h}$ under room temperature to remove any remaining solvent before the next analysis.

\subsection{Morphology Analysis of Electrospun PHA Fibrous Films}

The morphologies of electrospun fibrous films were observed and recorded using Scanning Electron Microscope (SEM, Leo Supra 50VP Field Emission and Hitachi Tabletop Scanning Electron Microscope, TM3000). A $5 \mathrm{~mm} \times 5 \mathrm{~mm}$ sized area was cut out from the fibrous film. The samples were mounted on aluminum stubs and then sputter-coated with gold. The samples were viewed under several magnification powers. The average diameter of PHA nanofibers was calculated by randomly measuring 100 different points on SEM images of each nanofiber film using AnalySis Image Analyser software.

\subsection{Preliminary In Vitro Paclitaxel Release Studies}

\subsubsection{In Vitro Degradation Studies of Electrospun $P(3 H B-c o-95$ mol\% 4HB) Fibrous Films in PBS Containing Porcine Pancreatic Lipase}

The electrospun $\mathrm{P}(3 \mathrm{HB}-\mathrm{co}-95 \mathrm{~mol} \% 4 \mathrm{HB})$ fibrous films were cut into an area of $1 \mathrm{~cm} \times 1 \mathrm{~cm}$. The weight of films was measured before immersing in a tube containing $2 \mathrm{~mL}$ of $0.1 \mathrm{M}$ phosphate buffered saline (PBS, pH 7.4) with dissolved porcine pancreatic lipase $(0.1 \mathrm{mg} / \mathrm{mL})$ and agitating in a shaker $(100 \mathrm{rpm})$ at 37 ${ }^{\circ} \mathrm{C}$. At every predetermined interval of time, the fibrous films were withdrawn, rinsed with sterile distilled water and dried in the fume hood until a constant weight was obtained. Control was served by immerging electrospun $\mathrm{P}(3 \mathrm{HB}-\mathrm{co}-95 \mathrm{~mol} \% 4 \mathrm{HB})$ fibrous films in PBS without porcine pancreatic lipase. The percentage weight loss of fibrous films was calculated according to formula (2): -

Percentage weight loss $(\%)=$

$[$ (Initial weight - dried sample weight $) \div$ Initial weight $] \times 100$

\subsubsection{HPLC Method Validation}

HPLC was used to detect and quantify the paclitaxel in PBS containing lipase and was validated before release studies. A serial dilution of six different concentrations ranging from $1.25-40 \mathrm{ppm}$ was prepared from a primary stock solution. Primary stock solution was spiked into PBS containing porcine pancreatic lipase. The mixture was mixed in a vortex shaker for at least $30 \mathrm{~s}$ to ensure thorough mixing, followed by serial 2-fold dilutions until all the desired concentrations were reached. Each solution was then diluted with acidified methanol at the ratio of 1:4, vortex mixed for approximately $30 \mathrm{~s}$ and centrifuged at 9000 $\mathrm{rpm}$ for $15 \mathrm{~min}$ at room temperature $\left(25^{\circ} \mathrm{C}\right)$. The supernatants were then injected in triplicates for HPLC analysis. The mobile phase for HPLC analysis comprised of acetonitrile, methanol and deionized water in the ratio of 65:5:30 (v: v) at a flow rate of 1 $\mathrm{mL} / \mathrm{min}$ under isocratic conditions. The injection volume was set at $50 \mu \mathrm{L}$ for a running time of $8 \mathrm{~min}$. The chromatogram was monitored at a wavelength of 227 $\mathrm{nm}$. A PBS-lipase solution served as blank control. The precision and accuracy tests were evaluated within-day and between days by using the mentioned serial dilutions with five replicates of each concentration for five consecutive days. Five different calibration curves of the mentioned six different concentrations were prepared to assay quality control measurements (QC). The precision of the method at each concentration was calculated as coefficient of variation $(\mathrm{CV})$ by calculating the average standard deviation as a percentage of the measured mean concentration. Meanwhile, the accuracy of the method was calculated based on the measured mean concentration as a percentage of the added concentration.

\subsubsection{Paclitaxel Release Studies}

The electrospun $\mathrm{P}(3 \mathrm{HB}-\mathrm{co}-95 \mathrm{~mol} \% 4 \mathrm{HB})$ fibrous films loaded with $1 \%$ and $5 \%(\mathrm{w} / \mathrm{w})$ paclitaxel were used in in vitro paclitaxel release studies. The fibrous films were cut into small pieces with an area of $1 \mathrm{~cm} \times$ $1 \mathrm{~cm}$. The fibrous films were then immersed in $2 \mathrm{~mL}$ of PBS containing porcine pancreatic lipase and agitated at $100 \mathrm{rpm}$ at $37^{\circ} \mathrm{C}$. The unloaded electrospun $\mathrm{P}(3 \mathrm{HB}-$ co-95mol\% $4 \mathrm{HB}$ ) fibrous films served as a control and the experiment was carried out in triplicates. The buffer solution was withdrawn at predetermined time intervals and the same volume of fresh buffer was replaced. The withdrawn solution was then analyzed using HPLC as described above.

\subsection{Preliminary Direct Coating of $\mathrm{P}(3 \mathrm{HB}-\mathrm{co}-95$ mol\% 4HB) on Metal Stent Studies}

Electrospining precursor solution was prepared according to section 2.4. The $\mathrm{P}(3 \mathrm{HB}-\mathrm{co}-95 \mathrm{~mol} \% 4 \mathrm{HB})$ 
solution concentration was reduced 2.5 times lower than $10 \%(\mathrm{w} / \mathrm{v})$. The ratio of PHA mass and paclitaxel loading was set at 1:1. The total volume of precursor solution was $1 \mathrm{~mL}$. A metal stent was placed on the metal collector, covered by a layer of plastic sheet in which an open circle of $5 \mathrm{~cm}$ in diameter had been cut. The applied voltage was set at $15 \mathrm{kV}$ with a fixed flow rate of $40 \mu \mathrm{L} / \mathrm{min}$ for $5 \mathrm{~min}$. The morphology of the stent coating was then observed using SEM.

\section{RESULTS AND DISCUSSION}

Electrospinning is a fundamentally simple process but involves many parameters concerning factors such as the polymer solution, process employed and ambient conditions. These parameters are usually used to facilitate the process and tune the system in order to obtain desired nanofibers or scaffold composition [25]. In this study, the influence of solution parameters (concentration and molecular weight), process parameters (applied voltage) and drug loading in the formation of PHA-based fibers during electrospinning was investigated. The effect on fiber morphology was also investigated, and preliminary drug release studies were carried out.

\subsection{Effect of Solution Concentration, Molecular Weight and Applied Voltage on PHA Fiber Formation and Morphology}

During electrospinning, polymer concentration and molecular weight are influential in determining whether fibers or beads are produced. Notably, polymer concentration, molecular weight and viscosity are correlated with each other [25-27]. In this study, $\mathrm{P}(3 \mathrm{HB})$ and $\mathrm{P}(3 \mathrm{HB}-\mathrm{co}-95 \mathrm{~mol} \% 4 \mathrm{HB})$, which have different molecular weights (Table 1), provide us an insight to shape the electrospinning optimization process. $\mathrm{P}(3 \mathrm{HB}-\mathrm{co}-95 \mathrm{~mol} \% 4 \mathrm{HB})$ revealed the good fit model to the trend of fiber formation. For $\mathrm{P}(3 \mathrm{HB}-\mathrm{Co}-95$ mol\% 4HB), beaded fibers were formed at a concentration of $8 \%$, representing the critical minimum concentration $\left(\mathrm{C}_{\mathrm{e}}\right)$, irrespective of applied voltage (Figure 1a-b). The number of polymer chain entanglements (physical locking) had reached the minimum requirement to allow some fibers to form. However, there was still insufficient viscosity to maintain the stability of the polymer jet, so beaded fibers were seen. Below $8 \%$ solution concentration, droplets or beads were produced at an applied voltage of $25 \mathrm{kV}$ (Figure 1c) due to insufficient physical locking in the dilute polymer solution [27]. This caused the polymer jet to break up into droplets before deposition on the metal collector. An increase in polymer solution concentration will result in greater polymer chain entanglement [28]. Therefore, the $\mathrm{P}(3 \mathrm{HB}-\mathrm{co}-95 \mathrm{~mol} \%$ $4 \mathrm{HB}$ ) solution concentration was increased to $10 \%$. At this concentration, the bead defect was completely removed at applied voltages above $25 \mathrm{kV}$, and smooth fibers were formed (Figure 1d-f). This indicated that chain entanglement was sufficient to stabilize the jet while travelling from tip to collector.

In the case of $\mathrm{P}(3 \mathrm{HB})$ solutions, bead-free fibers were obtained at a lower concentration of $2 \%$ at $25 \mathrm{kV}$ (Figure 2). This may have been aided by the molecular weight effect since polymer chain length or molecular weight $\left(M_{\mathrm{w}}\right)$ is directly proportional to the number of entanglements [27]. The polymer $M_{w}$ determines the amount of physical locking in the solution, as reflected in the solution viscosity $[25,29]$. Of the PHAs that we tested, $\mathrm{P}(3 \mathrm{HB})$ had a higher $M_{\mathrm{w}}$ of up to $13.4 \times 10^{5}$ compared to $\mathrm{P}(3 \mathrm{HB}-\mathrm{co}-95 \mathrm{~mol} \% 4 \mathrm{HB})$ with a $M_{\mathrm{w}}$ of 6.5 $\times 10^{5}$ (Table 1). Thus, even at low concentrations such as $2 \%, \mathrm{P}(3 \mathrm{HB})$ solutions already experienced sufficient physical locking to maintain the stability of the polymer jet and smooth nanofibers could be formed.

In principle, a threshold voltage is needed to initiate the electrospinning to produce fibers. When the threshold voltage is reached or exceeded, and if the electrostatic charge is sufficient to stretch the polymer solution, the electrospinning of fibers would be initiated [25]. Theoretically, increasing the voltage or electrical energy is expected to change the morphology of the nanofibers from bead to bead-defect fiber, and then to bead-free fiber. However, further increasing the applied

Table 1: The Monomer Composition, Weight Average Molecular Weight $\left(M_{\mathrm{w}}\right)$, Number Average Molecular Weight $\left(M_{\mathrm{n}}\right)$ and Polydispersity Index (PDI) of $\mathrm{P}(3 \mathrm{HB})$ and $\mathrm{P}(3 \mathrm{HB}-\mathrm{co}-95 \mathrm{~mol} \% 4 \mathrm{HB})$

\begin{tabular}{|c|c|c|c|c|c|}
\hline \multirow{2}{*}{ Polyhydroxyalkanoate (PHA) } & \multicolumn{5}{|c|}{ PHA composition and molecular weights } \\
\cline { 2 - 6 } & 3HB & 4HB & $\begin{array}{c}\left(\boldsymbol{M}_{\mathrm{w}}\right) \\
\left(\times 10^{5}\right)\end{array}$ & $\begin{array}{c}\left(\boldsymbol{M}_{\boldsymbol{n}}\right) \\
\left(\times 10^{5}\right)\end{array}$ & $\boldsymbol{M}_{\mathrm{w}} / \boldsymbol{M}_{\mathbf{n}}(\mathrm{PDI})$ \\
\hline \hline $\mathrm{P}(3 \mathrm{HB})$ & 100 & - & $13.4 \pm 0.2$ & $3.1 \pm 0.5$ & $4.3 \pm 0.4$ \\
\hline $\mathrm{P}(3 \mathrm{HB}-\mathrm{co}-4 \mathrm{HB})$ & 5 & 95 & $6.5 \pm 0.7$ & $3.1 \pm 0.2$ & $2.1 \pm 0.1$ \\
\hline
\end{tabular}




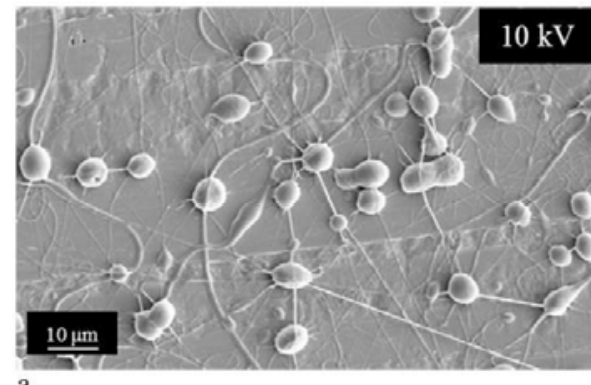

a

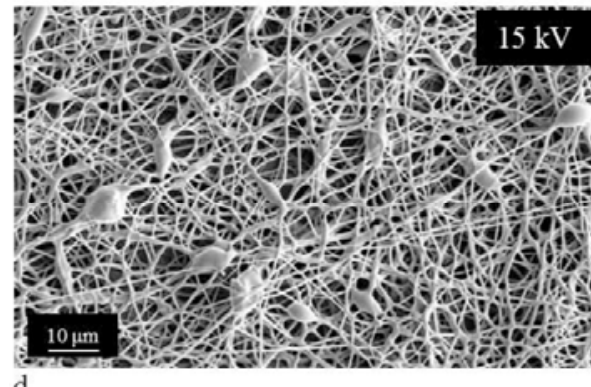

d
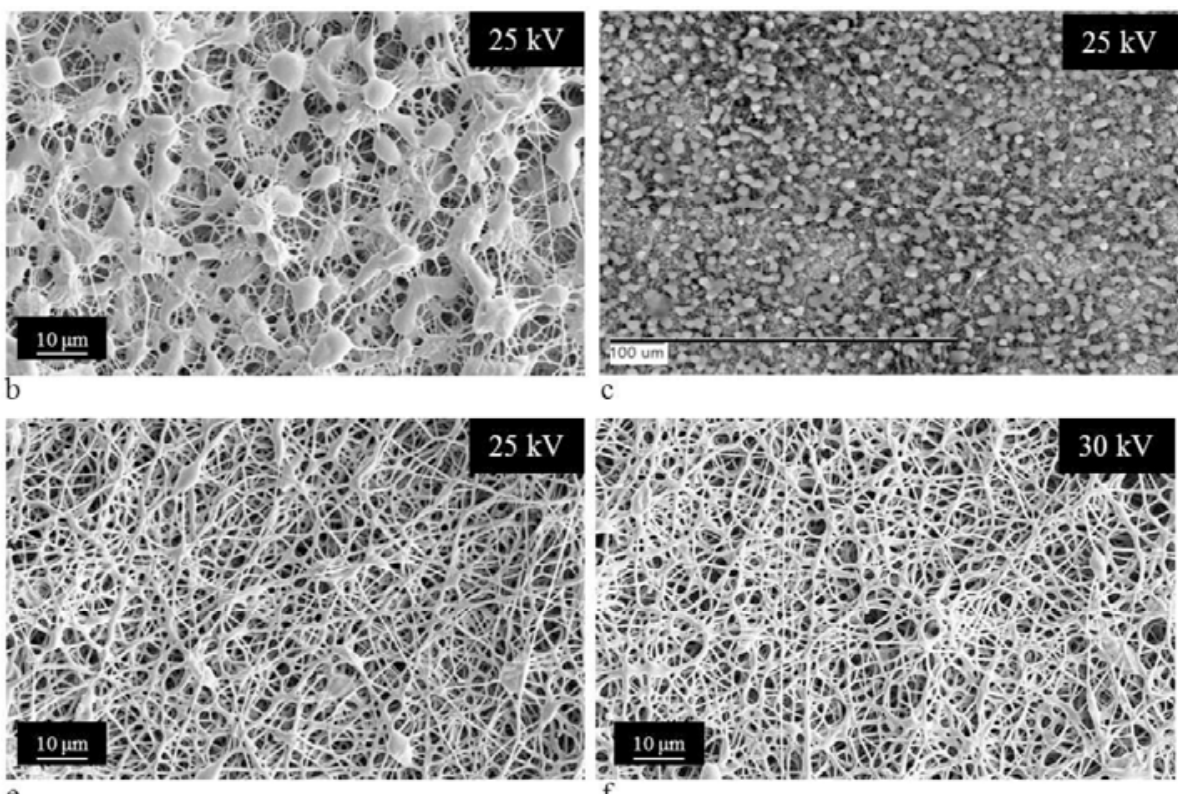

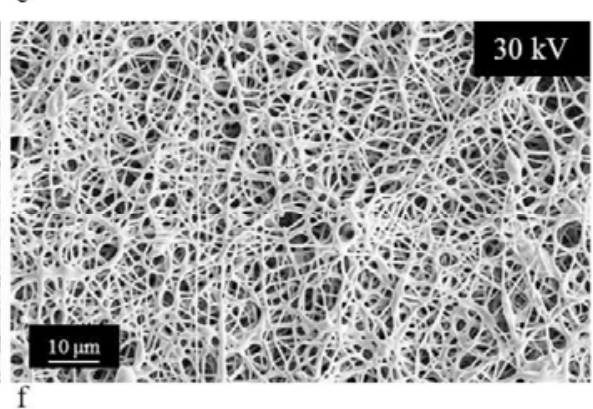

Figure 1: Morphology of electrospun $\mathrm{P}(3 \mathrm{HB}-\mathrm{co}-95 \mathrm{~mol} \% 4 \mathrm{HB})$ nanofibrous films at $8 \%$ solution concentration (a, b), $2 \%$ solution concentration (c) and $10 \%$ solution concentration $(\mathbf{d}-\mathbf{f})$. The magnification powers were $500 \times(\mathbf{a}, \mathbf{c})$ and $1000 \times(\mathbf{b}, \mathbf{d}-\mathbf{f})$.

voltage would again lead to the formation of beaded fibers due to disturbances to the cone stability [27, 30]. Based on our findings, the effect of applied voltage in producing smooth fibers was clearly observed only if the solution concentration (and hence, viscosity) is sufficient to support a stable jet. Below or at $C_{e}$, varying the applied voltage did not improve the morphology of electrospun $\mathrm{P}(3 \mathrm{HB}-\mathrm{co}-95 \mathrm{~mol} \% \mathrm{4HB})$ fibrous films (Figure 1a-b). However, for solution concentrations above $\mathrm{C}_{\mathrm{e}}$, at $10 \%$, bead-defect $\mathrm{P}(3 \mathrm{HB}-\mathrm{co}-95 \mathrm{~mol} \%$ $4 \mathrm{HB})$ fibers were seen at lower voltage $(15 \mathrm{kV})$. By increasing the applied voltage, beads were gradually removed and bead-free fibers could be obtained (Figure 1d-f).

\subsection{Effect of Solution Concentration, Molecular Weight and Applied Voltage on PHA Fiber Diameter}

In addition to the influence of solution concentration on the morphology of fibers, the effect of electrospinning parameters on the diameter of the nanofibers was also investigated. In previous reports, the effect of applied voltage on fiber diameter was negligible when the polymer concentration was low [29, 31,32 ]. In our experiments, the fiber diameter of both $\mathrm{P}(3 \mathrm{HB})$ and $\mathrm{P}(3 \mathrm{HB}-\mathrm{co}-95 \mathrm{~mol} \% 4 \mathrm{HB})$ fibers were not influenced by the applied voltage, which is in agreement with the literature. A similar range of fiber diameters was maintained with all applied voltages of both polymers. The range of average fiber diameter of $\mathrm{P}(3 \mathrm{HB})$ nanofibers at $2 \%$ solution concentration was approximately $210 \pm 80 \mathrm{~nm}$. Meanwhile, $\mathrm{P}(3 \mathrm{HB}-\mathrm{co}-95$ mol\% 4HB) nanofibers were in the range of $710 \pm 240$ $\mathrm{nm}$. Therefore, we investigated whether solution concentration is also the critical parameter for fiber diameter. It has previously been reported that polymer diameter varies with polymer concentrations and the distance between tip and collector [25]. As proposed by $\mathrm{Ki}$ et al. [33], (who reported that the solution concentration was directly proportional to fiber diameter through electrospinning of gelatin) larger fibers would be produced at higher solution concentration. Our results confirmed this, with $\mathrm{P}(3 \mathrm{HB}-\mathrm{co}-95 \mathrm{~mol} \% 4 \mathrm{HB})$ forming larger fibers than $\mathrm{P}(3 \mathrm{HB})$, due to the higher concentration required for the former $(10 \%)$ than the latter (2\%). On the other hand, the molecular weight of a polymer also affects the fiber diameter [27]. As discussed before, the molecular weight is correlated

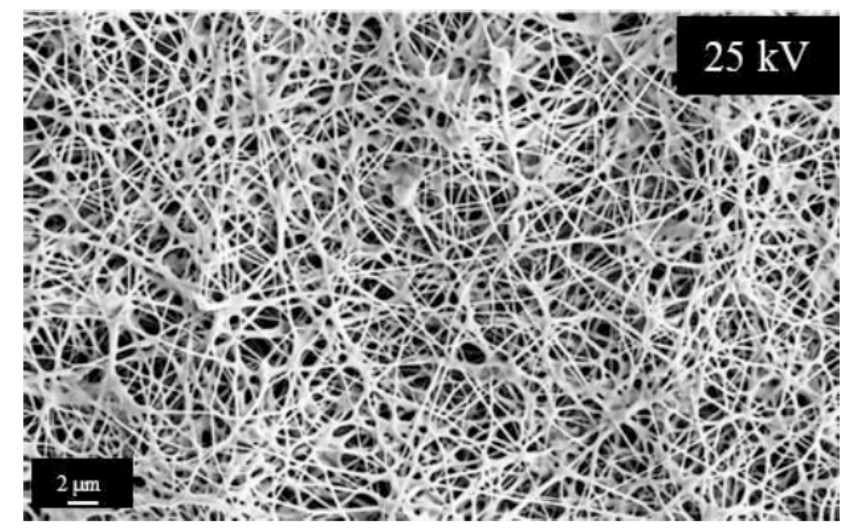

Figure 2: Morphology of electropun $\mathrm{P}(3 \mathrm{HB})$ nanofibrous film at $2 \%$ solution concentration. The magnification power was $1000 \times$. 


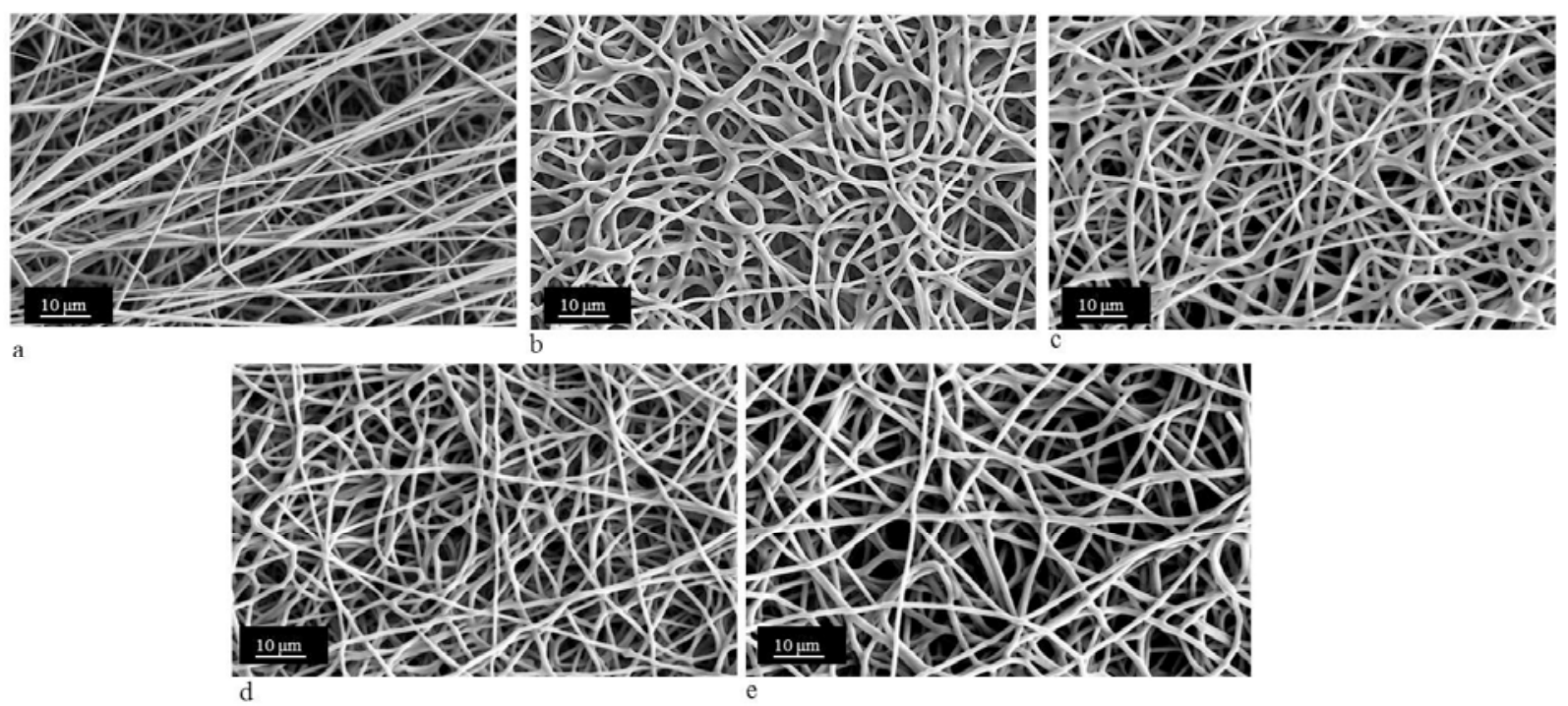

Figure 3: Morphology of electrospun $\mathrm{P}(3 \mathrm{HB}-\mathrm{co}-95 \mathrm{~mol} \%$ 4HB) nanofibrous films at different paclitaxel loadings, according to PHA mass. Paclitaxel loading rates were (a) $1 \%$ (b) $2 \%$ (c) $3 \%$ (d) $4 \%$ (e) $5 \%$. The power magnification of all SEM images was $1000 \times$.

with polymer chain entanglement. Polymers of higher molecular weight, such as $\mathrm{P}(3 \mathrm{HB})$, have fewer chains per unit volume. Hence, they show greater chain extensibility, facilitating the production of nanofibers with smaller diameters. In line with this expectation, our $\mathrm{P}(3 \mathrm{HB})$ nanofibers had smaller diameters than the $\mathrm{P}(3 \mathrm{HB}-\mathrm{co}-95 \mathrm{~mol} \%$ 4HB) nanofibers.

\subsection{Effect of Paclitaxel Loading on $\mathrm{P}(3 \mathrm{HB}-\mathrm{co}-95$ mol\% 4HB) Fibers}

Paclitaxel is known for its poor water solubility, leading it to be solubilized in organic solvents such as methanol, ethanol or dimethyl sulfoxide (DMSO) to facilitate delivery [22]. Both PHA and paclitaxel have hydrophobic characteristics, which therefore enhanced dissolution in our solvent system. Zeng et al. [34] reported that paclitaxel could be embedded in fibers using an appropriate polymer solvent system: i.e. paclitaxel is highly soluble in poly(L-lactic acid) (PLLA)/ $\mathrm{CHCl}_{3}$ /acetone solutions. The solvent is rapidly removed during elongation of the jet during electrospinning. Hence, the occurrence of phase separation is difficult under this circumstance. When solvent is completely evaporated, the drug tends to remain inside the nanofiber so that the drug is embedded in the dried nanofiber film. As can be seen in Figure 3, no small particles were found on the surface of $\mathrm{P}(3 \mathrm{HB}-\mathrm{co}-95 \mathrm{~mol} \% 4 \mathrm{HB})$ fibers at different paclitaxel loadings. This indicated that paclitaxel was entrapped in the fibers and was within the range of the carrying capacity of the fibers. The carrying capacity was, however, exceeded for $\mathrm{P}(3 \mathrm{HB})$, causing small particles which were suspected to be paclitaxel, to be found on the surface of the nanofibers (Figure 4). The number of small particles on the nanofibers' surface increased when paclitaxel loading increased from $5 \%$ to $20 \%$ but $\mathrm{P}(3 \mathrm{HB})$ fiber diameter remained within the same range for all loadings (data not shown). Contrasting results were obtained for $\mathrm{P}(3 \mathrm{HB}-\mathrm{co}-95$ mol\% 4HB) nanofibers, for which increasing paclitaxel loading caused an increment in average nanofiber diameter (Figure 5). The average nanofiber diameter of unloaded fibers was $620 \pm 160 \mathrm{~nm}$, while $1 \%$ of paclitaxel loading increased the average nanofiber diameter to $954 \pm 230 \mathrm{~nm}$. This provides strong evidence that paclitaxel increases electrospun PHA nanofiber diameter when entrapped within the polymer.

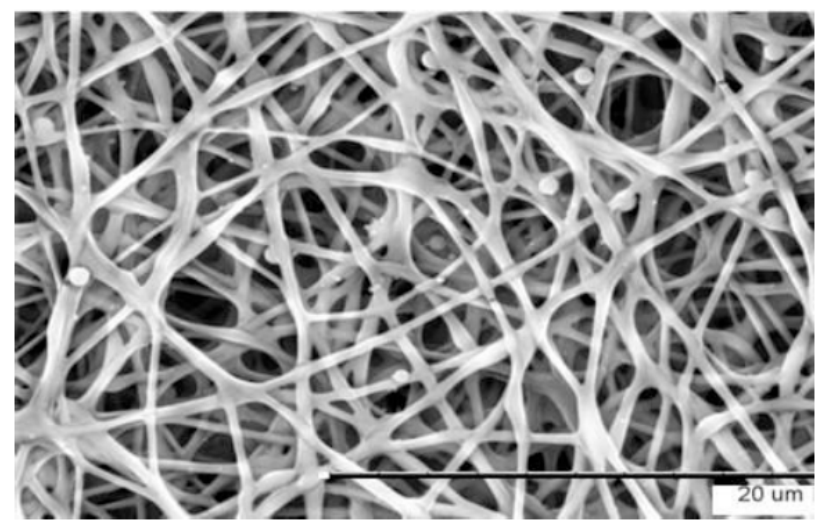

Figure 4: Small particles were found on the surface of $\mathrm{P}(3 \mathrm{HB})$ nanofibers when the carrying capacity was exceeded. The magnification power was $5000 \times$.

The increased nanofiber diameter with paclitaxel could be the result of a drug/polymer concentration 


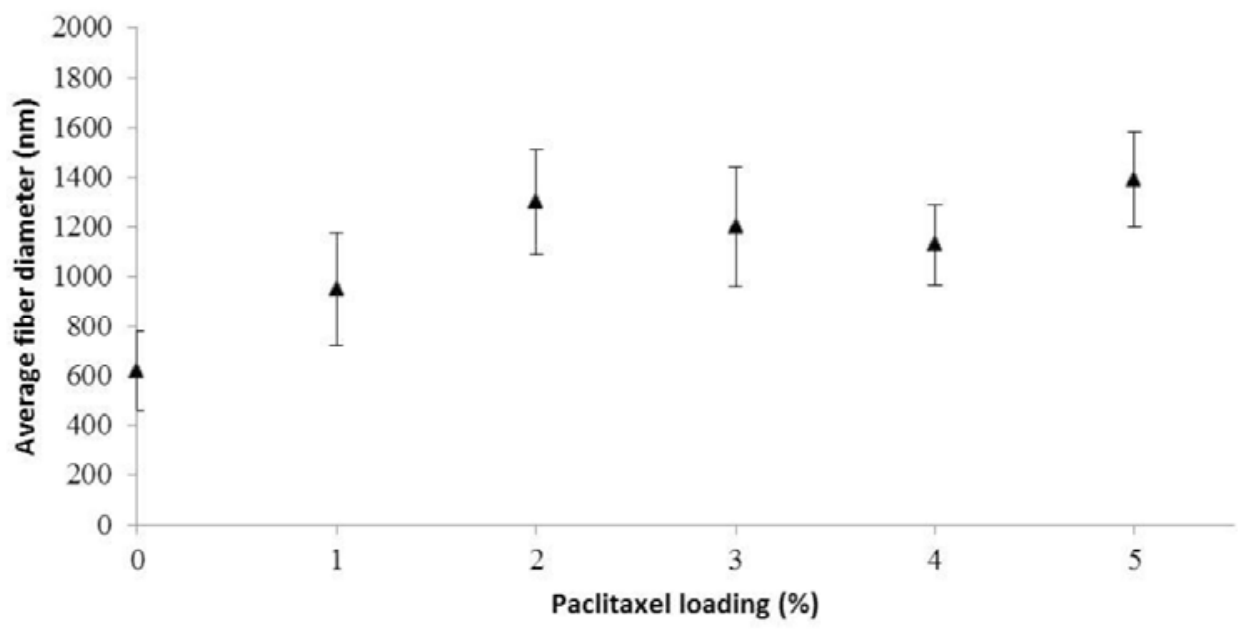

Figure 5: Paclitaxel loading ranging from 0 to $5 \%(\mathrm{w} / \mathrm{w})$ into $\mathrm{P}(3 \mathrm{HB}-\mathrm{co}-95 \mathrm{~mol} \% 4 \mathrm{HB})$ nanofibers at $10 \%$ polymer solution concentration. Data are the mean of 100 different points on nanofiber films SEM images.

interaction since the addition of the drug could affect the polymer solution viscosity [34]. Hence, we attempted to measure the effect of paclitaxel on the polymer viscosity by loading $1 \%$ paclitaxel into $8 \%$ $\mathrm{P}(3 \mathrm{HB}-\mathrm{co}-95$ mol\% $4 \mathrm{HB})$ precursor solution. Smooth and bead free fibers were formed when paclitaxel was added (Figure 6) instead of the bead-string morphology at the same initial polymer concentration without paclitaxel. This suggests that the dissolution of paclitaxel in a solvent system facilitates the production of smoother fibers by increasing the initial viscosity of polymer solution for a given concentration. Thus, higher loading of paclitaxel (and, potentially, other similar drugs) into the polymer/solvent system could further increase the polymer viscosity and contribute to larger fibers being produced.

\subsection{Preliminary Studies of Paclitaxel Release from Electrospun P(3HB-co-4HB) Fibrous Films}

The susceptibility of electrospun P(3HB-co-95 mol\% $4 \mathrm{HB})$ fibrous films to degradation by porcine pancreatic lipase was verified by immersing samples in buffered solutions of the enzyme. Weight loss values of up to 88 wt $\%$ were recorded after 2 weeks of treatment (Figure 7). The majority of weight loss occurred during the first $24 \mathrm{~h}$ with only very slight additional degradation subsequently. This could be due to the preferential degradation of amorphous areas of $4 \mathrm{HB}$ monomers followed by the slow degradation of remaining crystalline sections. No weight loss was detected in fibrous films that were placed in PBS without lipase, demonstrating that the fibrous films were not susceptible to hydrolysis by water. Based on previous findings by Ch'ng and co-workers [35, 36], porcine pancreatic lipase is equally effective in hydrolysing $\mathrm{P}(3 \mathrm{HB}-\mathrm{Co}-4 \mathrm{HB})$ as other lipases extracted from microbial sources [37, 38]. The HPLC method was also validated prior to drug release studies. Table 2 shows the accuracy and precision of our HPLC method for paclitaxel detection and determination in the PBSlipase system. The accuracy for within-day and between-day replicates was in the range of $92-109 \%$.
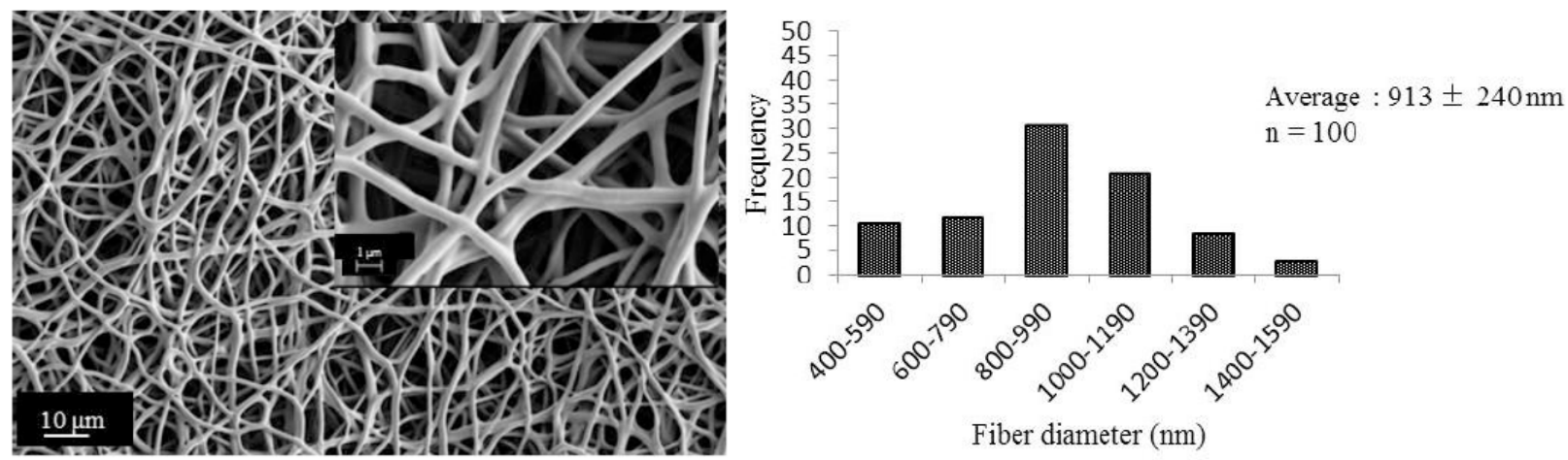

Figure 6: Smooth and bead-free $\mathrm{P}(3 \mathrm{HB}-\mathrm{co}-95 \mathrm{~mol} \%$ 4HB) nanofibers were formed after paclitaxel (1\%) was loaded into $8 \%$ $\mathrm{P}(3 \mathrm{HB}-\mathrm{co}-95 \mathrm{~mol} \% 4 \mathrm{HB})$ precursor solution. The main image shows a magnification power of $3000 \times$ while the insert shows $5000 \times$ magnification. 
Similarly, the precision values for within-day $(\mathrm{CV}<5$ $\%)$ and between-day (CV < $10 \%)$ replicates indicated the reliability and stability of our method and hence its suitability for this study.

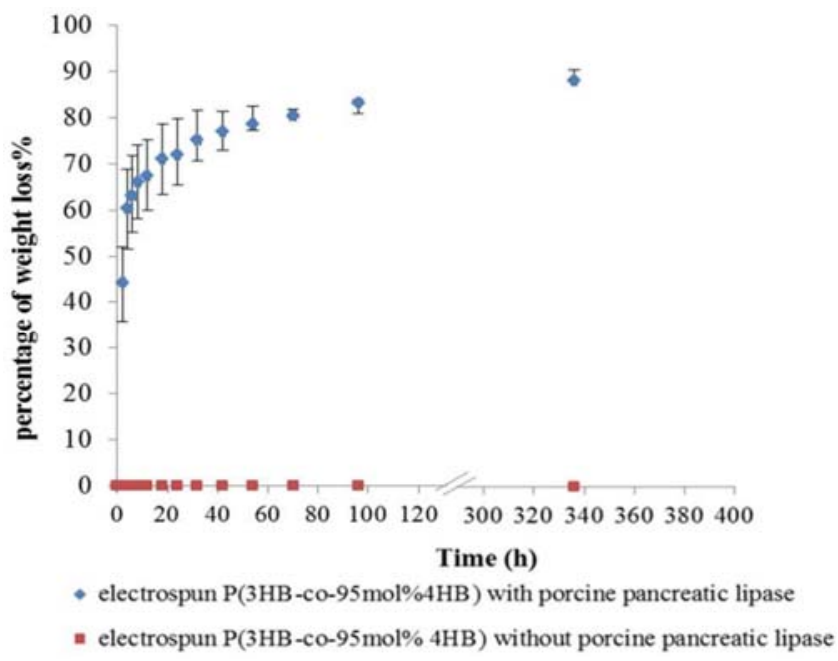

Figure 7: The percentage weight loss of electrospun $\mathrm{P}(3 \mathrm{HB}-$ co-95 mol\% 4HB) nanofibrous films in PBS $(0.1 \mathrm{M}, \mathrm{pH} 7.4)$ containing porcine pancreatic lipase $(0.1 \mathrm{mg} / \mathrm{mL})$. A control without lipase in the same buffer showed no weight loss.

Many factors have been found to affect the release of drugs from electrospun nanofibers [39-45]. In the present work, we found that drug loading had an important impact on the release of paclitaxel from P(3HB-co-95 mol\% 4HB) fibers. Higher paclitaxel loading $(5 \%)$ could cause more drug to be released from $\mathrm{P}(3 \mathrm{HB}-\mathrm{co}-95 \mathrm{~mol} \% 4 \mathrm{HB})$ fibers, at a faster rate than $1 \%$ loading during the first $10 \mathrm{~h}$ of incubation time (Figure 8a). However, the drug release pattern from high loading (5\%) fluctuated, with notable peaks at 4, 8 and $24 \mathrm{~h}$. Meanwhile, a more constant or controlled release pattern was observed at lower paclitaxel loading (1\%) (Figure $\mathbf{8 b}$ ). Notably, the electrospun fibrous films loaded with $5 \%$ paclitaxel were completely hydrolyzed at $24 \mathrm{~h}$ in PBS-lipase solution, while $1 \%$ loaded nanofibers took $36 \mathrm{~h}$ for complete degradation. In general, smaller nanofibers would favor faster drug release [46]. However, as discussed above, increasing the paclitaxel concentration increased nanofiber diameter. A possible reason for the slower hydrolysis of the smaller nanofibers with lower paclitaxel loading could be the arrangement of the nanofibers. As can be seen in Figure 3a, electrospun $\mathrm{P}(3 \mathrm{HB}-\mathrm{co}-95 \mathrm{~mol} \% 4 \mathrm{HB})$ fibrous films loaded with $1 \%$ paclitaxel show a more aligned fiber arrangement than at $5 \%$, which was a randomized nanofiber mat (Figure 3e). Based on the SEM images in the present study, the pore size in randomized fibrous films at higher drug loading (5\%) was larger. This could allow greater penetration of the PBS-lipase solution and so facilitate the enzymatic hydrolysis process and drug release. This is supported by the findings of Meng et al. [47] who reported that aligned poly(D,L-lactide-co-glycolide) (PLGA)/chitosan nanofibrous mats released fenbufen at a slower rate than randomly arranged mats. This was because the pore size of fibrous films was reduced, which reduced the diffusion of fenbufen from within the aligned nanofiber mat.

\subsection{Direct Coating of Metal Stent Via Electrospinning of $\mathrm{P}(3 \mathrm{HB}-\mathrm{co}-95 \mathrm{~mol} \% \mathrm{4HB})$ - Paclitaxel Fibers}

Concurrent to the fabrication and development of electrospun PHA nanofibers containing paclitaxel, we have also tested the possibility of coating metal stents directly via the electrospinning process. Our results show that the $\mathrm{P}(3 \mathrm{HB}-\mathrm{co}-95 \mathrm{~mol} \% 4 \mathrm{HB})$ fiber containing paclitaxel resulted in the formation of a continuous and homogeneous fibrous layer around the metal stent (Figure 9). By reducing the polymer concentration to 4 $\%$, with an increase in paclitaxel loading, we observed

Table 2: The Within-Day and Between-Day Precision and Accuracy Values of Concentration Measurements for Standard Paclitaxel Spiked into PBS Containing Porcine Pancreatic Lipase $(0.1 \mathrm{mg} / \mathrm{mL})$ and $\mathrm{Measured}$ by HPLC

\begin{tabular}{|c|c|c|c|c|c|c|c|c|}
\hline \multirow{2}{*}{$\begin{array}{c}\text { Concentration of } \\
\text { spiked paclitaxel } \\
(\mathbf{p p m})\end{array}$} & Mean & $\begin{array}{c}\text { Accuracy } \\
\text { \% of true } \\
\text { value) }\end{array}$ & $\begin{array}{c}\text { Precision } \\
\text { CV (\%) }\end{array}$ & $\begin{array}{c}\text { Discrepancy } \\
(\%)\end{array}$ & Mean & $\begin{array}{c}\text { Accuracy } \\
\text { (\% of true } \\
\text { value) }\end{array}$ & $\begin{array}{c}\text { Precision } \\
\text { CV (\%) }\end{array}$ & $\begin{array}{c}\text { Discrepancy } \\
(\%)\end{array}$ \\
\hline \hline 1.25 & 1.24 & 105.2 & 0.9 & 0.5 & 1.29 & 103.3 & 3.2 & -3.3 \\
\hline 2.5 & 2.49 & 105.7 & 0.9 & 0.4 & 2.44 & 97.7 & 6.2 & 2.3 \\
\hline 5.0 & 4.48 & 96.1 & 0.9 & 3.9 & 4.59 & 91.9 & 4.5 & 8.1 \\
\hline 10.0 & 9.89 & 99.0 & 0.6 & 1.1 & 9.63 & 96.3 & 3.4 & 3.7 \\
\hline 20.0 & 20.13 & 98.9 & 0.6 & 1.6 & 20.16 & 100.8 & 5.0 & -0.8 \\
\hline 40.0 & 41.91 & 103.5 & 0.2 & -4.8 & 43.52 & 108.8 & 2.5 & -8.8 \\
\hline
\end{tabular}



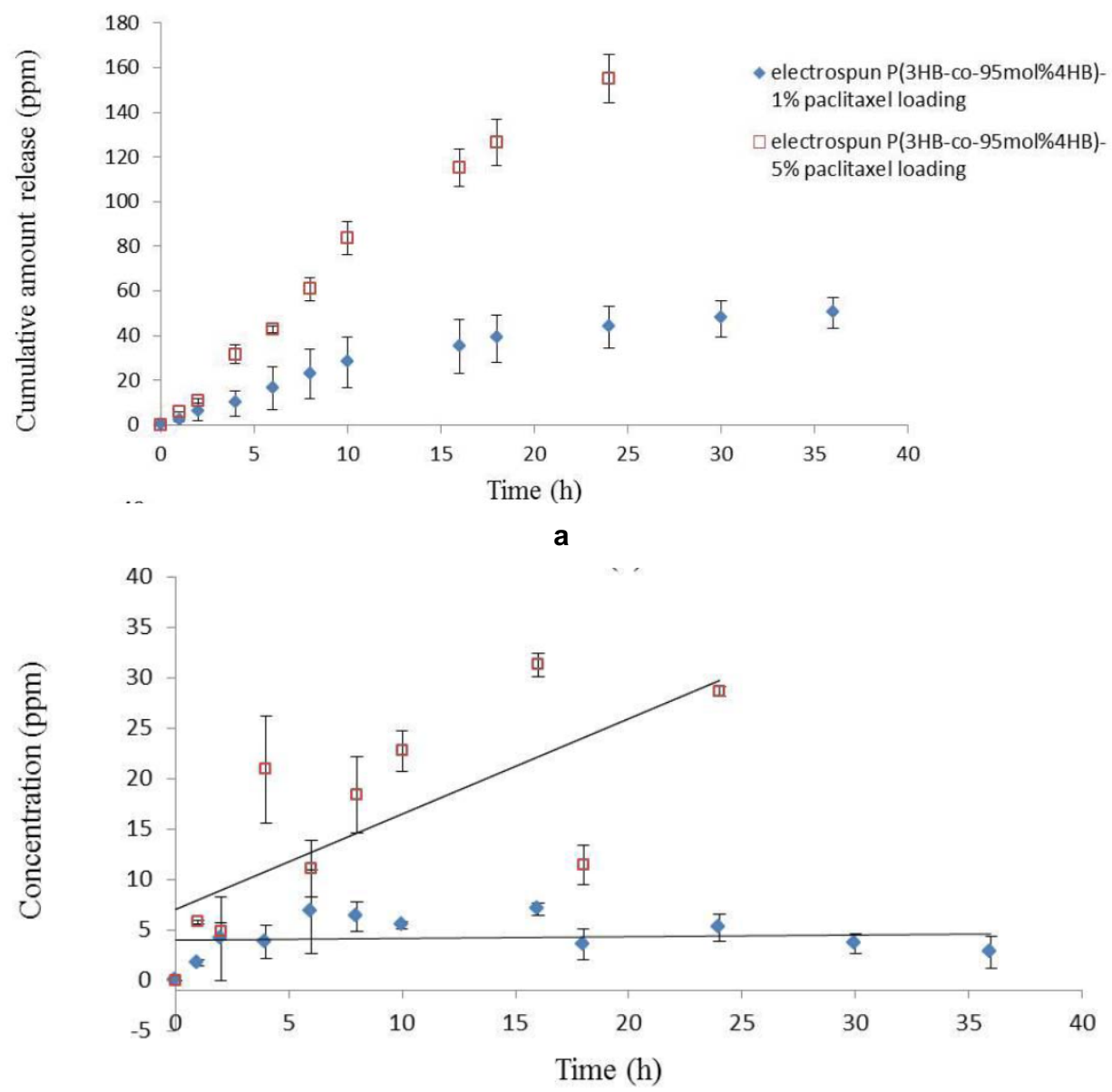

b

Figure 8: (a) Cumulative release (b) Time-point release of paclitaxel from electrospun $\mathrm{P}(3 \mathrm{HB}-\mathrm{co}-95 \mathrm{~mol} \% 4 \mathrm{HB})$ at $1 \%$ (diamond) and $5 \%$ (square) paclitaxel loading over time. Data values are the mean of triplicate experiments.

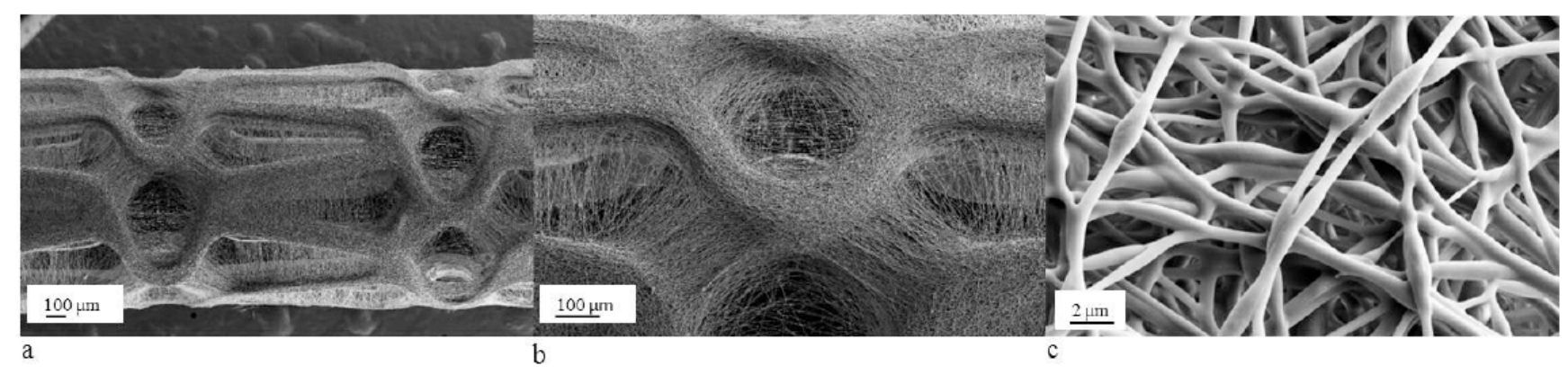

Figure 9: Direct coating of paclitaxel loaded $\mathrm{P}(3 \mathrm{HB}-\mathrm{co}-95 \mathrm{~mol} \% 4 \mathrm{HB})$ nanofibers onto a metal stent. The SEM images show different magnification powers of (a) $40 \times$ (b) $100 \times$ (c) $5000 \times$ for the same sample.

that the fibers were very uniform and formed a continuous porous layer around the stent. As mentioned earlier, the drug loading was shown to increase the initial polymer solution viscosity. Thus, we inferred that adding paclitaxel increased the solution viscosity sufficiently to create a more stable jet during electrospinning. This in turn created a favorable coating on the metal stent. Further studies are required, and are currently being carried out in this direction, in order to elucidate the mechanisms and critical parameters that are necessary to fully control this process.

\section{CONCLUSIONS}

Polymer molecular weight and solution concentration were much more influential than applied voltage in forming bead-free nanofibers and achieving a favorable morphology during electrospinning of PHA 
nanofiber films. High molecular weight PHA such as $\mathrm{P}(3 \mathrm{HB})$ produced fine fibers at low concentrations. In contrast, at the same concentration, lower molecular weight PHA [P(3HB-co-95 mol\% 4HB)] did not sustain sufficient physical locking and so formed beads along the length of the nanofibers. Hence, a 5 -fold higher solution concentration was necessary to resolve the bead defect fibers at higher applied voltage.

Addition of paclitaxel into the polymer solution significantly altered the initial polymer solution viscosity and was therefore able to eliminate bead formation at lower P(3HB-co-95 mol\% 4HB) solution concentrations. Paclitaxel also caused an increase in the diameter of nanofibers. We concluded that the fiber arrangement could explain differences in the drug release pattern for different loading rates of paclitaxel. At low drug loading, the drug release pattern of PHA fibers was relatively more constant and controlled than for higher drug loads. This could be due to a more aligned fiber arrangement at low drug loading that probably hindered the outward diffusion of paclitaxel from the nanofiber mat.

Finally, we have shown an example of how the drug-containing PHA fiber can be electrospun directly onto a metal stent in order to form a biocompatible coating. This could potentially serve as a controlled drug-eluting polymer to prevent restenosis.

\section{ACKNOWLEDGEMENTS}

YFL would like to express her gratitude to the MyBrain Program (provided by Ministry of Higher Education, Malaysia) and USM Fellowship for the financial support for this project. This study was funded by USM's Top-Down Research Grant (URICAS).

\section{REFERENCES}

[1] Yoo HS, Kim TG, Park, TG. Surface-funtionalized electrospun nanofibers for tissue engineering and drug delivery. Adv Drug Deliv Rev 2009; 61: 1033-42. http://dx.doi.org/10.1016/i.addr.2009.07.007

[2] Vasita R, Katti DS. Nanofibers and their applications in tissue engineering. Int J Nanomedicine 2006; 1: 15-30. http://dx.doi.org/10.2147/nano.2006.1.1.15

[3] Greiner A, Wendorff JH. Electrospinning: a fascinating method for the preparation of ultrathin fibers. Angew Chem Int Ed Engl 2007; 46: 5670-703. http://dx.doi.org/10.1002/anie.200604646

[4] Liang D, Hsiao BS, Chu B. Functional electrospun nanofibrous scaffolds for biomedical applications. Adv Drug Deliv Rev 2007; 59: 1392-412. http://dx.doi.org/10.1016/j.addr.2007.04.021

[5] Pillay V, Dott C, Choonara YE, et al. A review of the effect of processing variables on the fabrication of electrospun nanofibers for drug delivery applications. J Nanomater 2013 Article ID 789289, 22 pages.

http://dx.doi.org/10.1155/2013/789289

[6] Joyyi L, Sridewi N, Abdullah AAA, Kasuya K, Sudesh K. Fabrication and degradation of electrospun polyhydroxyalkanoate film. J Sib Fed Univ Biol 2015; 8: 23653.

http://dx.doi.org/10.17516/1997-1389-2015-8-2-236-253

[7] Brigham CJ, Sinskey AJ. Applications of polyhydroxyalkanoates in the medical industry. Int $\mathrm{J}$ Biotech Well Indus 2012; 1: 53-60.

http://dx.doi.org/10.6000/1927-3037.2012.01.01.03

[8] Sudesh K, Abe H, Doi Y. Synthesis, structure and properties of polyhydroxyalkanoates: biological polyesters. Prog Polym Sci 2000; 25: 1503-55 http://dx.doi.org/10.1016/S0079-6700(00)00035-6

[9] Thomson N, Summers D, Sivaniah E. Synthesis, properties and uses of bacterial storage lipid granules as natural occurring nanoparticles. Soft Matter 2010; 6: 4045-57. http://dx.doi.org/10.1039/b927559b

[10] Bhubalan K, Lee WH, Sudesh K. Polyhydroxyalkanoate. In: AJ Domb, N Kumar, A. Ezra, John Wiley \& Sons, Inc. Biodegradable polymers in clinical use and clinical development. Hoboken: New Jersey 2011; pp. 249-315.

[11] Martin DP, Williams, SF. Medical application of poly-4hydroxybutyrate: a strong flexible absorbable biomaterial. Biochem Eng J 2003; 16: 97-105 http://dx.doi.org/10.1016/S1369-703X(03)00040-8

[12] Siew EL, Rajab NF, Annear BO, Sudesh K, Inayat-Hussain, $\mathrm{SH}$. In vitro biocompatibility evaluation of poly(3hydroxybutyrate-co-4-hydroxybutyrate) copolymer in fibroblast cells. J Biomed Mater Res 2007; 81A: 317-25. http://dx.doi.org/10.1002/jbm.a.31000

[13] Siew EL, Rajab NF, Annear BO, Sudesh K, Inayat-Hussain $\mathrm{SH}$. Mutagenesis and clastogenic characterization of post sterilized poly(3-hydroxybutyrate-co-4-hydroxybutyrate) copolymer biosynthesized by Delftia acidovorans. J Biomed Mater Res A 2009; 91A: 786-94.

http://dx.doi.org/10.1002/jbm.a.32290

[14] Nelson T, Kaufman E, Kline J, Sokoloff L. The extraneural distribution of $\mathrm{Y}$-hydroxybutyrate. $\mathrm{J}$ Neurochem 1981; 37: 1345-8.

http://dx.doi.org/10.1111/j.1471-4159.1981.tb04689.x

[15] Sendelbeck SL, Girdis GL. Disposition of a ${ }^{14} \mathrm{C}$-labeled bioerodible polyorthoester and its hydrolysis products, 4 hydroxybutyrate and cis, trans-1,4-bis(hydroxymethyl) cyclohexane, in rats. Drug Metab Dispos 1985; 13: 291-5.

[16] Yu D, Zhu L, White K, Branford-White C. Electrospun nanofiber-based drug delivery systems. Health 2009; 1: 6775.

http://dx.doi.org/10.4236/health.2009.12012

[17] Long HJ. Paclitaxel (Taxol): a novel anticancer chemotherapeutic drug. Mayo Clin Proc 1994; 69: 341-5. http://dx.doi.org/10.1016/S0025-6196(12)62219-8

[18] Cahan MA, Walter KA, Colven OM, Brem H. Cytotoxicity of taxol in vitro against human and rat malignant brain tumors. Cancer Chemother Pharmacol 1994; 33: 441-4. http://dx.doi.org/10.1007/BF00686276

[19] Arbuck SG, Christian MC, Fisherman JS, et al. Clinica development of Taxol. J Natl Cancer Inst Monogr 1993; 15: 11-24

[20] Foa R, Norton L, Seidman AD. Taxol (paclitaxel) a novel micro-tubule agent with remarkable anti-neoplastic activity. Int J Clin Lab Res 1994; 24: 6-14. http://dx.doi.org/10.1007/BF02592403

[21] Rowinsky EK, Donehower RC. Paclitaxel (Taxol). N Engl J Med 1995; 332: 1004-14. http://dx.doi.org/10.1056/NEJM199504133321507 
[22] Singla AK, Garg A, Aggarwal D. Palitaxel and its formulations. Int J Pharm 2002; 235: 179-92. http://dx.doi.org/10.1016/S0378-5173(01)00986-3

[23] Lee WH, Azizan MNM, Sudesh K. Effects of culture conditions on the composition of poly(3-hydroxybutyrate-co4-hydroxybutyrate) synthesized by Comamonas acidovorans. Polym Degrad Stab 2004; 84: 129-34.

http://dx.doi.org/10.1016/..polymdegradstab.2003.10.003

[24] Braunegg G, Sonnleitner B, Lafferty RM. A rapid gas chromatographic method for the determination of poly- $\beta$ hydroxybutyric acid in microbial biomass. Eur $\mathrm{J}$ Microbiol Biotechnol 1978; 6: 29-37.

http://dx.doi.org/10.1007/BF00500854

[25] Bhardwaj N, Kundu SC. Electrospinning: A fascinating fiber fabrication technique. Biotechnol Adv 2010; 28: 325-47. http://dx.doi.org/10.1016/j.biotechadv.2010.01.004

[26] Luo CJ, Nangrejo M, Edirisinghe MA. Novel method of selecting solvents for polymer electrospinning. Polymer 2010; 51: 1654-62.

http://dx.doi.org/10.1016/.j.polymer.2010.01.031

[27] Shenoy SL, Bates WD, Frisch HL, Wnek GE. Role of chain entanglement on fiber formation during electrospinning of polymer solutions: good solvent, non-specific polymerpolymer interaction limit. Polymer 2005; 46: 3372-84. http://dx.doi.org/10.1016/j.polymer.2005.03.011

[28] Ramakrishna S, Fujihara K, Teo WE, Lim TC, Ma Z. An introduction to electrospinning and nanofibers. Singapore: World Scientific; 2005

[29] Tan SH, Inai R, Kotaki M, Ramakrishna S. Systematic parameter study for ultra-fine fiber fabrication via electrospinning process. Polymer 2005; 46: 6128-34.

http://dx.doi.org/10.1016/j.polymer.2005.05.068

[30] Deitzel JM, Kleinmeyer J, Harris D, Beck Tan NC. The effect of processing variables on the morphology of electrospun nanofibers and textiles. Polymer 2001; 42: 261-72. http://dx.doi.org/10.1016/S0032-3861(00)00250-0

[31] Reneker DH, Chun I. Nanometre diameter fibres of polymer, produced by electrospinning. Nanotechnology 1996; 7: 21623.

http://dx.doi.org/10.1088/0957-4484/7/3/009

[32] Demir MM, Yilgor I, Yilgor E, Erman B. Electrospinning of polyurethane fibers. Polymer 2002; 43: 3303-9. http://dx.doi.org/10.1016/S0032-3861(02)00136-2

[33] Ki CS, Baek DH, Gang KD, Lee KH, Um IC, Park YH. Characterization of gelatin nanofiber prepared from gelatinformic acid solution. Polymer 2005; 46: 5094-102. http://dx.doi.org/10.1016/j.polymer.2005.04.040

[34] Zeng J, Xu X, Chen X, et al. Biodegradable electrospun fibers for drug delivery. J Control Release 2003; 92: 227-31. http://dx.doi.org/10.1016/S0168-3659(03)00372-9

[35] Ch'ng DHE, Sudesh K. Densitometry based microassay for the determination of lipase depolymerizing activity on polyhydroxyalkanoate. AMB Express 2013; 3: 22. http://dx.doi.org/10.1186/2191-0855-3-22
[36] Ch'ng DHE, Lee WH, Sudesh K. Biosynthesis and lipasecatalysed hydrolysis of 4-hydroxybutyrate-containing polyhydroxyalkanoates from Delftia acidovorans. Mal J Microbiol 2012; 8: 156-63.

[37] Mukai K, Doi Y, Sema Y, Tomita K. Substrate specificities in hydrolysis of polyhydroxyalkanoates by microbial esterases. Biotechnol Lett 1993; 15: 601-4.

http://dx.doi.org/10.1007/BF00138548

[38] Hsieh WC, Wada Y, Chang CP. Fermentation, biodegradation and tensile strength of poly(3hydroxybutyrate-co-4-hydroxybutyrate) synthesized by Delftia acidovorans. J Taiwan Inst Chem Eng 2009; 40: 1437.

http://dx.doi.org/10.1016/i.jtice.2008.11.004

[39] Okuda T, Tominaga K, Kidoaki S. Time-programmed dual release formulation by multilayered drug-loaded nanober meshes. J Control Release 2009; 143: 258-64. http://dx.doi.org/10.1016/i.jconrel.2009.12.029

[40] Cui W, Li X, Zhu X, Yu G, Zhou S, Weng J. Investigation of drug release and matrix degradation of electrospun poly(DLlactide) fibers with paracetanol inoculation. Biomacromolecules 2006; 7: 1623-9. http://dx.doi.org/10.1021/bm060057z

[41] Xie Z, Buschle-Diller G. Electrospun poly(D,L-lactide) fibers for drug delivery: The influence of cosolvent and the mechanism of drug release. J Appl Polym Sci 2010; 115: 1-8. http://dx.doi.org/10.1002/app.31026

[42] Kenawy ER, Bowlin GL, Mansfield K, et al. Release of tetracycline hydrochloride from electrospun poly(ethylene-covinylacetate), poly(lactic acid), and a blend. J Control Release 2002; 81: 57-64. http://dx.doi.org/10.1016/S0168-3659(02)00041-X

[43] Buschle-Diller G, Cooper J, Xie Z, Wu Y, Waldrup J, Ren X. Release of antibiotics from electrospun bicomponent fibers. Cellulose 2007; 14: 553-62.

http://dx.doi.org/10.1007/s10570-007-9183-3

[44] Zamani M, Morshed M, Varshosaz J, Jannesari M. Controlled release of metronidazole benzoate from poly epsiloncaprolactone electrospun nanobers for periodontal diseases. Eur J Pharm Biopharm 2010; 75: 179-85. http://dx.doi.org/10.1016/j.ejpb.2010.02.002

[45] Zeng J, Yang L, Liang Q, et al. Influence of the drug compatibility with polymer solution on the release kinetics of electrospun fiber formulation. J Control Release 2005; 105: 43-51.

http://dx.doi.org/10.1016/j.jconrel.2005.02.024

[46] Goonoo N, Bhaw-Luximon A, Jhurry D. Drug loading and release from electrospun biodegradable nanofibers. J Biomed Nanotechnol 2014; 10: 2173-99. http://dx.doi.org/10.1166/jbn.2014.1885

[47] Meng ZX, Zheng W, Li L, Zheng YF. Fabrication, characterization and in vitro drug release behavior of electrospun PLGA/chitosan nanofibrous scaffold. Mater Chem Phys 2011; 125: 606-11.

http://dx.doi.org/10.1016/j.matchemphys.2010.10.010

Received on 17-11-2015

Accepted on 02-12-2015

Published on 18-01-2016

\section{DOI: http://dx.doi.org/10.6000/1927-3037.2015.04.04.1}

(C) 2015 Lee et al.; Licensee Lifescience Global.

This is an open access article licensed under the terms of the Creative Commons Attribution Non-Commercial License (http://creativecommons.org/licenses/by-nc/3.0/) which permits unrestricted, non-commercial use, distribution and reproduction in any medium, provided the work is properly cited. 